Case Report

\title{
Cecal Endometriosis Presenting as Acute Appendicitis
}

\author{
Hamidreza Alizadeh Otaghvar, ${ }^{1}$ Mostafa Hosseini,, ${ }^{1}$ Ghazaal Shabestanipour, ${ }^{2}$ \\ Adnan Tizmaghz, ${ }^{1}$ and Gandom Sedehi Esfahani ${ }^{1}$ \\ ${ }^{1}$ Rasool-e-Akram Hospital, Iran University of Medical Sciences, Tehran 1449614535, Iran \\ ${ }^{2}$ Shemiranat Health Center, Shahid Beheshti University of Medical Sciences, Tehran 1985717443, Iran \\ Correspondence should be addressed to Adnan Tizmaghz; adnan_ti@yahoo.com
}

Received 26 April 2014; Accepted 19 June 2014; Published 9 July 2014

Academic Editor: Paola De Nardi

Copyright (c) 2014 Hamidreza Alizadeh Otaghvar et al. This is an open access article distributed under the Creative Commons Attribution License, which permits unrestricted use, distribution, and reproduction in any medium, provided the original work is properly cited.

\begin{abstract}
The aim of our paper is to show the diagnosis of Coecal endometriosis as an infrequent reason of right iliac fossa pain. cecal endometriosis manifesting with right lower quadrant pain is difficult to diagnose, and it may even sometimes require laparotomy for diagnosis and treatment. We report here a case of cecal endometriosis causing clinically resembled acute appendicitis. In our patient, a diagnosis of cecal endometriosis was made postoperatively by microscopic examination of excised right colon, and the patient symptoms and general condition were improved after the surgery (open right hemicolectomy and ileocolic anastomosis).
\end{abstract}

\section{Introduction}

Endometriosis is defined as an ectopic proliferation of endometrial tissue outside the uterine cavity [1]. It is fairly common in childbearing women. Bowel involvement in endometriosis is uncommon and usually localized in the rectosigmoid and less frequently in the cecum.

\section{Caser Report}

A 43-year-old woman with no medical history was admitted to the hospital with a one-day history of right iliac fossa pain, nausea, and vomiting. Her menses had been irregular, with occasional dysmenorrhea. The abdominal examination revealed right lower quadrant tenderness. The white blood cell count was $10900 / \mathrm{mm}^{3}$. On abdominal ultrasound, calcified appendicolith is seen as a hyperechoic focus at caecoappendiceal junction. A diagnosis of acute appendicitis was made clinically and the patient underwent McBurney incision for open appendectomy. There were multiple lymphadenitis in the mesoappendix and abnormal shaped coecum with a brown-colored planed mass on the base of the appendix that extended to the wall of the coecum, measuring $3 \mathrm{~cm}$ in diameter (Figure 1). No other similar lesions were found. The uterus and the ovary were normal. A standard right hemicolectomy was performed by laparotomy after consulting the gynecologist.

The pathologic examination showed ectopic endometrial glands in the thickened muscular propria and the subserosa of the cecal wall. The mucosa was not involved. There was no microscopical evidence of acute appendicitis.

Patient's postoperative course was uneventful and she was addressed to gynecologist.

\section{Discussion}

It has been estimated that 4 to $17 \%$ of all menstruating women have endometriosis $[1,2]$; bowel involvement occurs in 3 to $37 \%$ of the cases, with $3.5 \%$ of cecum localization [3].

Clinically, cecal endometriosis may mimic a number of diseases such as Crohn's disease, appendicitis, tuboovarian abscess, cecal diverticulitis or pseudodiverticulitis, and ileocecal tuberculosis [4-8]. Also, it can take the form of chronic or recurrent abdominal pain or dyschezia. Endometriosis of the intestines is usually on the outside wall and consists of small patches. However, there are some cases where endometriosis grows to infiltrate to the inside of the intestines. This is when the symptom of blood in the stool occurs [3, $9-11]$. And it can even cause ileocolic intussusception [12,13] or bowel obstruction [14]. Hence, the differential diagnosis, 


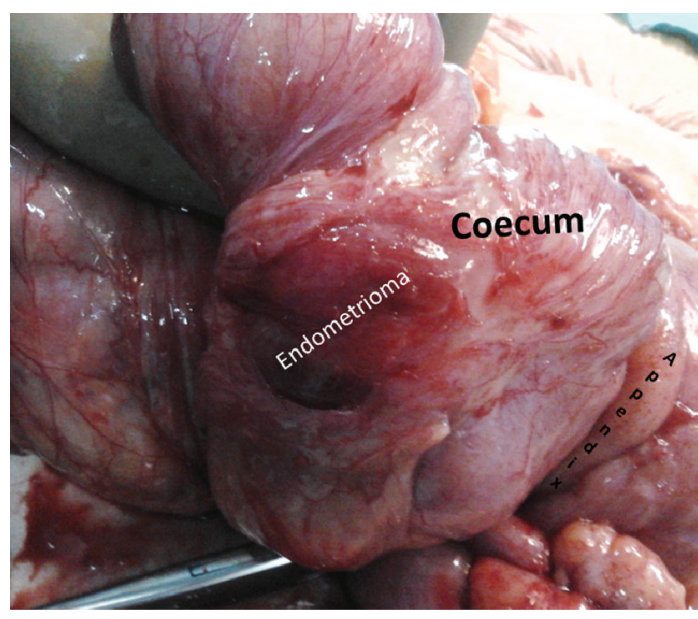

FIGURE 1

especially in emergency setting, is difficult. Bowel troubles are usually cyclic and associated with the period $[3,4]$. Our patient presented clinically with acute appendicitis. Although she had had irregular menses and occasional dysmenorrhea, cecal or appendiceal endometriosis was never suspected preoperatively. When she was questioned again postoperatively, she described similar pain several months ago but with no relationship to menstrual cycle and she had not had any other symptoms of endometriosis: constipation, dyschezia, and so forth.

Since Nezhat described in 2001 the first laparoscopic bowel resection for endometriosis [15], many studies have been published on this topic and, recently, Daraï et al. have demonstrated, in a prospective trial, that laparoscopy is a safe option in the treatment of bowel endometriosis and offers a high pregnancy rate and a good quality of life [16].

As mucosal invasion by an endometrioma is quite rare, an accurate diagnosis is often difficult to make without surgery. Campagnacci et al. [3] reported seven cases of colorectal endometriosis with a normal mucosa at colonoscopy in all cases. At the same time, there are no radiologic or diagnostic imaging findings that are specific for endometriosis [5]. Both the evaluation of symptoms and clinical examination are inadequate for an accurate diagnosis of intestinal endometriosis $[12,13]$. Therefore, ultrasonographic or radiological techniques are required to confirm this diagnosis before surgery [1]. Although no gold standard is universally accepted for the diagnosis of bowel endometriosis, magnetic resonance imaging (MRI) is one of the most commonly used techniques. A study comprising 195 patients with suspected endometriosis demonstrated that MRI has a sensitivity of $88 \%$, a specificity of $98 \%$, a positive predictive value of $95 \%$, a negative predictive value of $95 \%$, and an accuracy of $95 \%$ in diagnosing intestinal endometriosis [17]. These findings were subsequently confirmed by several other investigations [1821]. However, in some cases, the diagnosis of intestinal endometriosis by MRI may be difficult because nodules with small hemorrhagic content have a signal intensity very close to that of the surrounding muscular structures [22]. Therefore, the injection of ultrasonography jelly in the vagina and the rectum during MRI has been proposed to facilitate the identification of intestinal lesions [23]. Pelvic ultrasonography, computed tomography, and magnetic resonance imaging are occasionally used to identify individual lesions, but these modalities are not helpful in assessing the extent of endometriosis [24]. Some studies mentioned that laparoscopic evaluation is the gold standard for the definitive diagnosis of endometriosis. However, because of the heterogeneous appearance of the lesions, the accuracy of laparoscopic diagnosis depends on the ability of the surgeon to recognize the disease [4]. Unequivocal diagnosis requires microscopic examination [3]. In our case, endometriosis was not suspected on the macroscopic appearance. And right hemicolectomy was performed to avoid neglecting a malignant tumor.

\section{Conclusion}

Although cecal endometriosis is a little rare, it should be considered in female patients with right lower quadrant pain. Surgery is still the treatment of choice to avoid neglecting malignant tumor and some complications such as perforation, bowel obstruction, or bleeding. But using biopsy and frozen section might help in avoiding a "bioptic hemicolectomy." Gynecologic intraoperatory counseling might have been very useful in these cases.

\section{Conflict of Interests}

There is no conflict of interests to report by any of the authors.

\section{References}

[1] M. G. Muto, M. J. O’Neill, and E. Oliva, "Case 18-2005: a 45year-old woman with a painful mass in the abdomen," The New England Journal of Medicine, vol. 352, no. 24, pp. 2535-2542, 2005.

[2] G. M. Honoré, "Extra pelvic endometriosis," Clinical Obstetrics and Gynecology, vol. 42, pp. 699-673, 1999.

[3] R. Campagnacci, S. Perretta, M. Guerrieri et al., "Laparoscopic colorectal resection for endometriosis," Surgical Endoscopy and Other Interventional Techniques, vol. 19, no. 5, pp. 662-664, 2005.

[4] M. Varras, E. Kostopanagiotou, K. Katis, C. H. Farantos, Z. Angelidou-Manika, and S. Antoniou, "Endometriosis causing extensive intestinal obstruction simulating carcinoma of the sigmoid colon: a case report and review of the literature," European Journal of Gynaecological Oncology, vol. 23, no. 4, pp. 353-357, 2002.

[5] S. H. Bromberg, J. Waisberg, M. I. Franco, C. V. Oliveira, R. G. Lopes, and A. C. Godoy, "Surgical treatment for colorectal endometriosis," International Surgery, vol. 84, no. 3, pp. 234238, 1999.

[6] C. Villarreal-Peral, L. Olvera-Gracida, L. González-MaynesMde, and G. Saucedo-Ruiz, "Appendicular endometriosis as a cause of acute abdomen," Ginecología y Obstetricia de México, vol. 79, no. 8, pp. 489-492, 2011.

[7] T. Toporcer, P. Harbul'ak, H. Baumöhlová, L. Lakyová, and J. Radonak, "Pseudodiverticulitis coeci-the atypical etiology of right iliac fossa pain-a case report," Rozhledy $v$ Chirurgii, vol. 89, no. 6, pp. 379-383, 2010. 
[8] A. U. Mukhtar, "Ileo-caecal tuberculosis mimicking colonic tumour-case report," Central African Journal of Medicine, vol. 46, no. 2, pp. 44-45, 2000.

[9] A. Stepniewska, P. Pomini, M. Scioscia, L. Mereu, G. Ruffo, and L. Minelli, "Fertility and clinical outcome after bowel resection in infertile women with endometriosis," Reproductive BioMedicine Online, vol. 20, no. 5, pp. 602-609, 2010.

[10] E. Daraï, B. Lesieur, G. Dubernard, R. Rouzier, M. Bazot, and M. Ballester, "Fertility after colorectal resection for endometriosis: results of a prospective study comparing laparoscopy with open surgery," Fertility and Sterility, vol. 95, no. 6, pp. 1903-1908, 2011.

[11] E. Daraï, M. Carbonnel, G. Dubernard et al., "Determinant factors of fertility outcomes after laparoscopic colorectal resection for endometriosis," European Journal of Obstetrics Gynecology and Reproductive Biology, vol. 149, no. 2, pp. 210-214, 2010.

[12] R. Emmanuel, M. Léa, P. Claude et al., "Ileocolic intussusception due to a cecal endometriosis: case report and review of literature," Diagnostic Pathology, vol. 7, article 62, no. 1, 2012.

[13] E. Denève, O. Maillet, P. Blanc, J. M. Fabre, and D. Nocca, "Ileocecal intussusception secondary to a cecal endometriosis," Journal de Gynecologie, Obstetrique et Biologie de la Reproduction's, vol. 37, no. 8, pp. 796-798, 2008.

[14] R. Chaer, A. Sam II, M. Teresi, and J. Cintron, "Endometriosisinduced acute small and large bowel obstruction: rare clinical entities," The New Zealand Medical Journal, vol. 118, no. 1217, 2005.

[15] F. Nezhat, "Laparoscopic segmental resection for infiltrating endometriosis of the rectosigmoid colon: a preliminary report," Surgical Laparoscopy, Endoscopy \& Percutaneous Techniques, vol. 11, pp. 67-68, 2001.

[16] E. Daraï, G. Dubernard, C. Coutant, C. Frey, R. Rouzier, and M. Ballester, "Randomized trial of laparoscopically assisted versus open colorectal resection for endometriosis: morbidity, symptoms, quality of life, and fertility," Annals of Surgery, vol. 251, no. 6, pp. 1018-1023, 2010.

[17] M. Bazot, E. Darai, R. Hourani et al., "Deep pelvic endometriosis: MR imaging for diagnosis and prediction of extension of disease," Radiology, vol. 232, no. 2, pp. 379-389, 2004.

[18] M. S. Abrao, M. O. da C Gonçalves, J. A. Dias Jr., S. Podgaec, L. P. Chamie, and R. Blasbalg, "Comparison between clinical examination, transvaginal sonography and magnetic resonance imaging for the diagnosis of deep endometriosis," Human Reproduction, vol. 22, no. 12, pp. 3092-3097, 2007.

[19] M. Bazot, C. Lafont, R. Rouzier, G. Roseau, I. ThomassinNaggara, and E. Daraï, "Diagnostic accuracy of physical examination, transvaginal sonography, rectal endoscopic sonography, and magnetic resonance imaging to diagnose deep infiltrating endometriosis," Fertility and Sterility, vol. 92, no. 6, pp. 18251833, 2009.

[20] C. Chapron, M. Vieira, N. Chopin et al., "Accuracy of rectal endoscopic ultrasonography and magnetic resonance imaging in the diagnosis of rectal involvement for patients presenting with deeply infiltrating endometriosis," Ultrasound in Obstetrics and Gynecology, vol. 24, no. 2, pp. 175-179, 2004.

[21] L. P. Chamié, R. Blasbalg, M. O. Gonçalves, F. M. Carvalho, M. S. Abrão, and I. S. de Oliveira, "Accuracy of magnetic resonance imaging for diagnosis and preoperative assessment of deeply infiltrating endometriosis," International Journal of Gynecology and Obstetrics, vol. 106, no. 3, pp. 198-201, 2009.

[22] E. Biscaldi, S. Ferrero, V. Remorgida, E. Fulcheri, and G. A. Rollandi, "Rectosigmoid endometriosis with unusual presentation at magnetic resonance imaging," Fertility and Sterility, vol. 91, no. 1, pp. 278-280, 2009.

[23] P. Loubeyre, P. Petignat, S. Jacob, J. Egger, J. Dubuisson, and J. Wenger, "Anatomic distribution of posterior deeply infiltrating endometriosis on MRI after vaginal and rectal gel opacification," American Journal of Roentgenology, vol. 192, no. 6, pp. 1625-1631, 2009.

[24] D. L. Olive and L. B. Schwartz, "Medical Progress: Endometriosis," The New England Journal of Medicine, vol. 328, no. 24, pp. 1759-1769, 1993. 


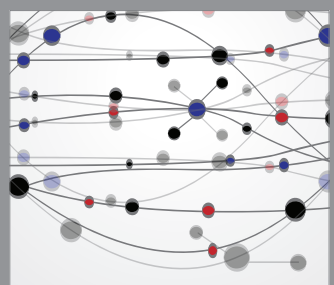

The Scientific World Journal
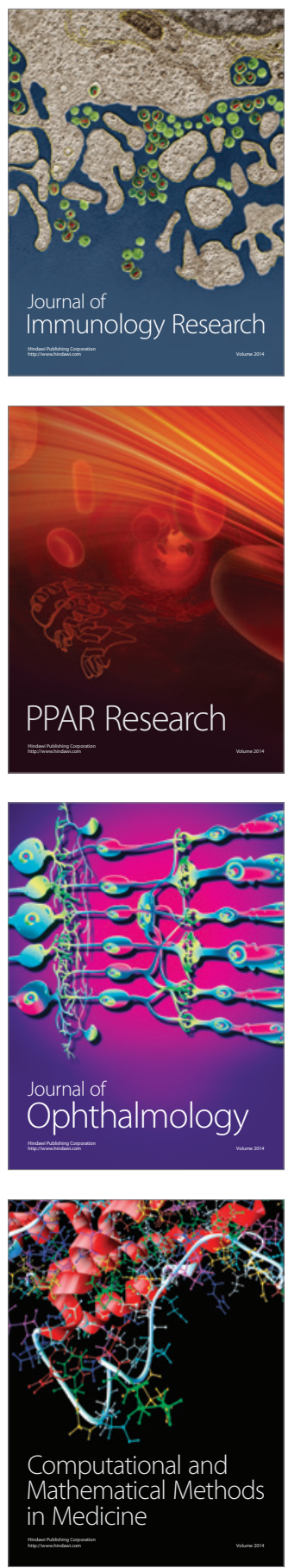

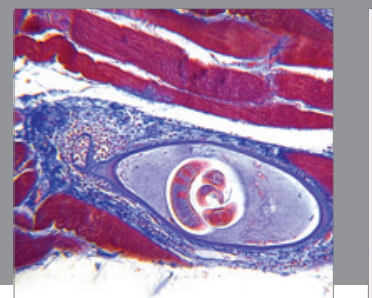

Gastroenterology

Research and Practice
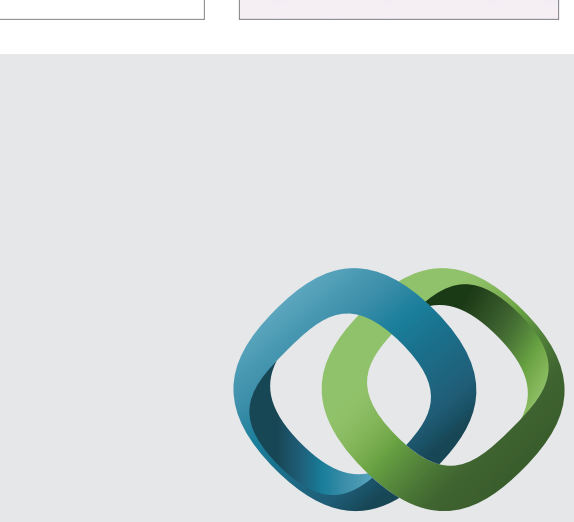

\section{Hindawi}

Submit your manuscripts at

http://www.hindawi.com
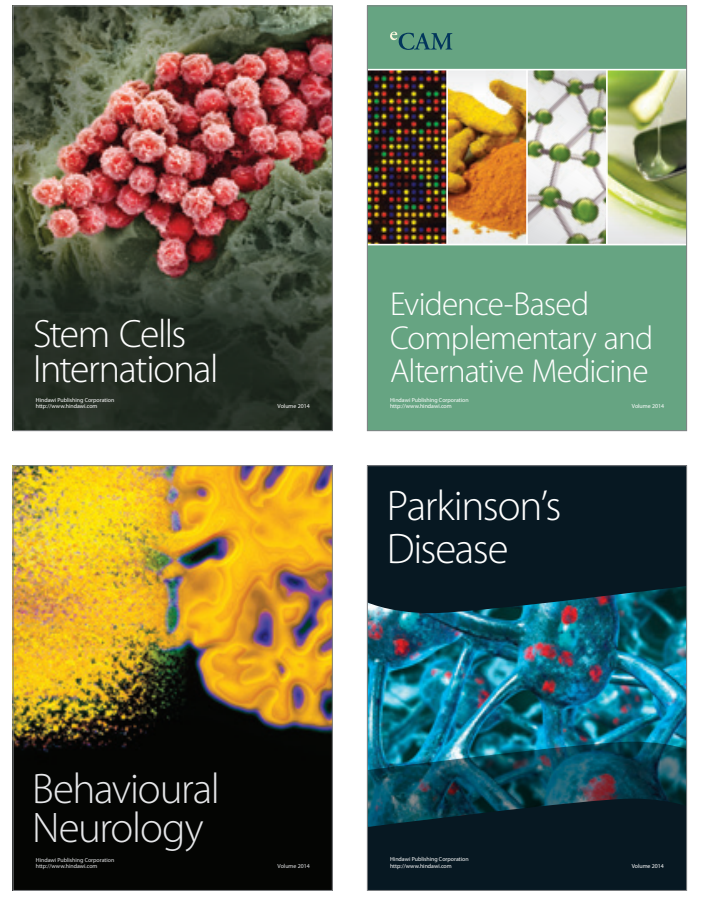
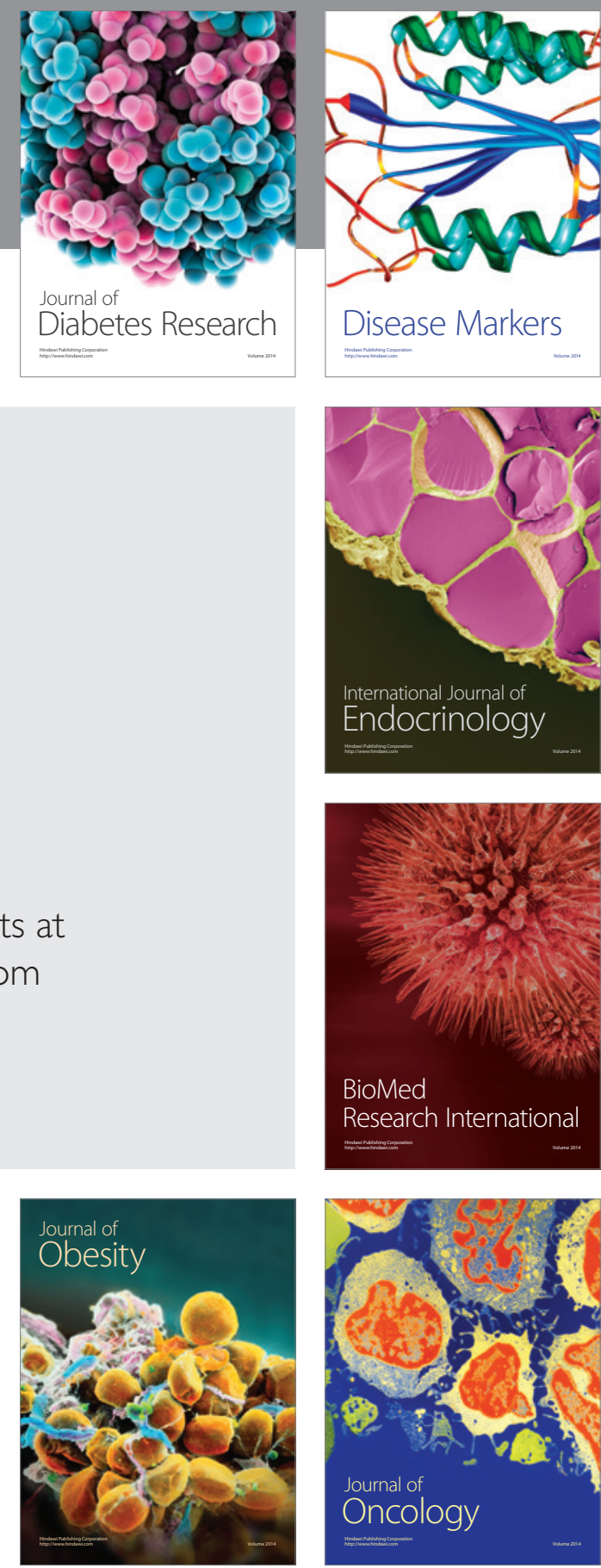

Disease Markers
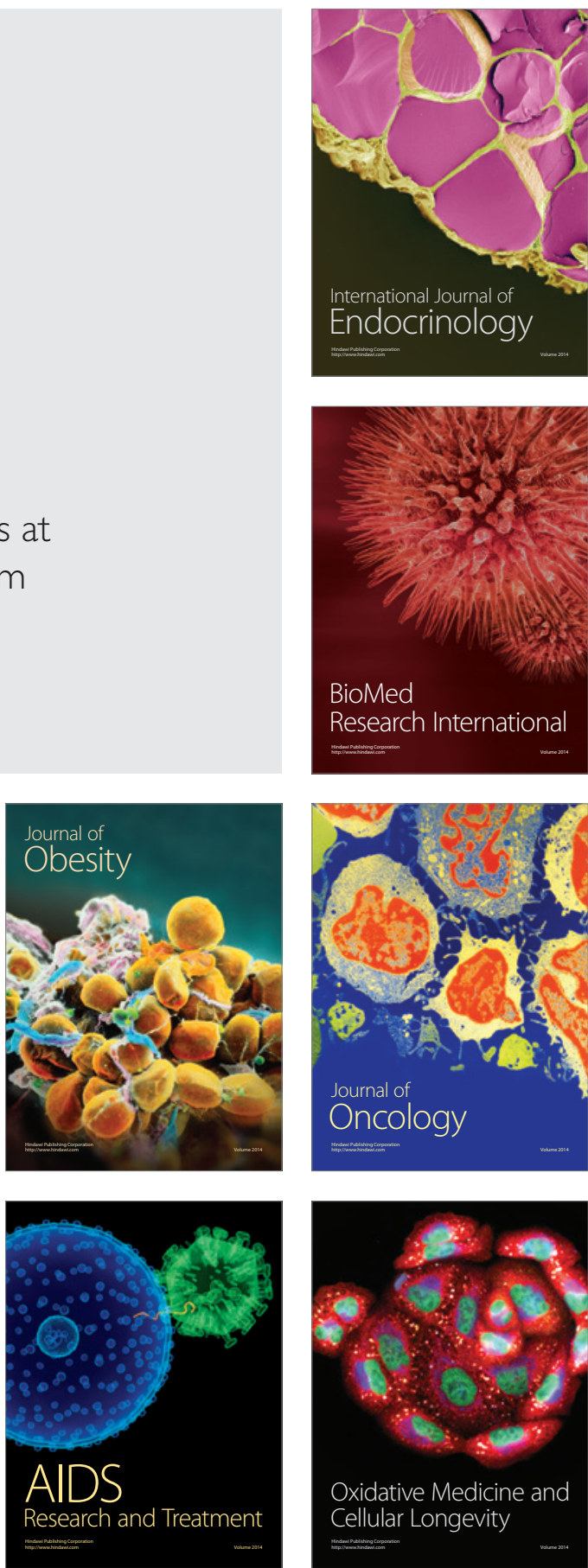